Original Article

\title{
Effects of bedside self-exercise on oropharyngeal swallowing function in stroke patients with dysphagia: a pilot study
}

\author{
Young-SeOK $\mathrm{ChO}^{1)}$, Dong-Hwan OH${ }^{2)}$, Young-Rim Paik ${ }^{3)}$, JeOng-Hoon LeE ${ }^{4}$, Ji-Su Park ${ }^{5}$ * \\ 1) Department of Occupational Therapy, Hyejeon College, Republic of Korea \\ 2) Department of Occupational Therapy, Kyungdong University, Republic of Korea \\ 3) Department of Occupational Therapy, Doowon Technical University, Republic of Korea \\ 4) Department of Occupational Therapy, St. Paul Catholic University, Republic of Korea \\ 5) Department of Rehabilitation Science, Graduate School of Inje University: 197 Inje-ro, Gimhae, \\ Gyeongsangnam-do 621-749, Republic of Korea
}

\begin{abstract}
Purpose] The purpose of this study was to investigate the effect of self-exercise on oropharyngeal swallowing function in patients with dysphagia. [Subjects and Methods] Nine patients with dysphagia after stroke were recruited. Self-exercise including effortful swallowing, tongue strengthening, and shaker exercise was performed 5 times a week for 4 weeks. Swallowing function was evaluated using the videofluoroscopic dysphagia scale (VDS) based on a videofluoroscopic swallowing study. [Results] There were significant differences in both the oral and pharyngeal phases of the VDS before and after the intervention. [Conclusion] This study demonstrated that bedside self-exercise is a positive method to improve oropharyngeal swallowing function in patients with dysphagia after stroke.

Key words: Dysphagia, Exercise, Stroke
\end{abstract}

(This article was submitted Jun. 9, 2017, and was accepted Jul. 12, 2017)

\section{INTRODUCTION}

Oropharyngeal dysphagia treatment can be divided into remedial and compensatory strategies. The remedial strategy aims to improve actual swallowing function through various exercises and maneuvers ${ }^{1}$, including tongue strengthening, shaker exercise, and effortful swallowing ${ }^{2-4}$. These have demonstrated various effects on oropharyngeal swallowing function, such as improved oral function, increased elevation of the larynx, reduced residue in the pharynx, decreased aspiration, and increased opening of the esophageal sphincter ${ }^{2}$,5). Therefore, it is important not only to apply various remedial strategies in the clinical setting, but also to educate patients on how to perform these self-exercises in order to maximize their effects. Therefore, this study investigated the effect of self-exercise on swallowing function in patients with dysphagia after stroke. The institutional review board of Inje University approved the study, and all participants provided informed, written consent prior to involvement in the study.

\section{SUBJECTS AND METHODS}

Participants $(n=9)$ were recruited from the dysphagia clinic in the rehabilitation department of a local hospital. Inclusion criteria were as follows: (1) oropharyngeal dysphagia after stroke confirmed by a videofluoroscopic swallowing study (VFSS), (2) no significant cognitive problems (Mini-Mental State Examination score $>24$ ), and (3) able to actively cooperate.

*Corresponding author. Ji-Su Park (E-mail: jisu627@hanmail.net)

(C2017 The Society of Physical Therapy Science. Published by IPEC Inc.

(c) (i) $(-)$ This is an open-access article distributed under the terms of the Creative Commons Attribution Non-Commercial No DerivaBY NG ND tives (by-nc-nd) License. (CC-BY-NC-ND 4.0: http://creativecommons.org/licenses/by-nc-nd/4.0/) 
Exclusion criteria were as follows: (1) secondary stroke, (2) severe communication difficulties associated with aphasia, and (3) neck pain or neck surgery. This study conducted 3 types of training. The training method was based on methods reported in previous studies ${ }^{2,3,6)}$. First, effortful swallowing was performed. Patients were instructed to press the tongue firmly against the palatewhile swallowing as hard as possible; this was repeated 30 times a day. Second, tongue strengthening was performed. Patients were instructed to press the tongue strongly against the hard palate; this also was repeated 30 times a day. Third, shaker exercise was performed. Patients were instructed to lift the head while in the lying position; isometric exercise was maintained for 60 seconds and isotonic exercise was repeated 30 times a day. All patients were educated on the first day by the occupational therapist, and were supervised by the caregiver in the ward for 4 weeks. Oropharyngeal swallowing function was assessed using the videofluoroscopic dysphagia scale (VDS) based on a VFSS before and after the intervention. The VDS consists of 7 items of the oral and pharyngeal phases of swallowing, respectively. To evaluate the effects of the intervention, the Wilcoxon signed-rank test was used to compare measures before and after the intervention in each patient. All statistical analyses were performed using SPSS version 15.0 (SPSS Inc., Chicago, IL, USA).

\section{RESULTS}

The pre- and post intervention results showed a significant decrease in the oral phase of the VDS from $17.8 \pm 4.2$ to 14.5 $\pm 4.3(\mathrm{p}<0.05)$. The pharyngeal phase also decreased significantly from $43.9 \pm 6.5$ to $41.9 \pm 5.3(\mathrm{p}<0.05)$.

\section{DISCUSSION}

This study was conducted to investigate the effect of self-exercise on swallowing function in patients with dysphagia after stroke. We observed significant differences in both the oral and pharyngeal phases after the intervention. Therefore, this study demonstrated that self-exercise has a positive effect on swallowing function improvement. In this study, effortful swallowing, tongue strengthening, and shaker exercise were performed. These methods can be performed by the patient without the help of a therapist. Previous studies have shown that effortful swallowing enhances the suprahyoid muscle, which contributes to increased laryngeal motion ${ }^{7)}$. Tongue strengthening is effective to increase the strength of the tongue, which is reported to have a positive effect on improving oral function as well as reducing aspiration in the pharyngeal phase ${ }^{2)}$. Shaker exercise also enhances the suprahyoid muscle in patients with dysphagia after stroke, and as a result, is effective to increase hyoid movement, reduce residue in the pharynx, reduce aspiration, and increase opening of the upper esophageal sphincter ${ }^{8,9)}$. These previous studies support the results of our study. In conclusion, self-exercise is an important strategy to improve swallowing function in patients with dysphagia.

\section{REFERENCES}

1) Park JS, Oh DH, Hwang NK, et al.: Effects of neuromuscular electrical stimulation combined with effortful swallowing on post-stroke oropharyngeal dysphagia: a randomised controlled trial. J Oral Rehabil, 2016, 43: 426-434. [Medline] [CrossRef]

2) Kim HD, Choi JB, Yoo SJ, et al.: Tongue-to-palate resistance training improves tongue strength and oropharyngeal swallowing function in subacute stroke survivors with dysphagia. J Oral Rehabil, 2017, 44: 59-64. [Medline] [CrossRef]

3) Park JS, Hwang NK, Oh DH, et al.: Effect of head lift exercise on kinematic motion of the hyolaryngeal complex and aspiration in patients with dysphagic stroke. J Oral Rehabil, 2017, 44: 385-391. [Medline] [CrossRef]

4) Clark HM, Shelton N: Training effects of the effortful swallow under three exercise conditions. Dysphagia, 2014, 29: 553-563. [Medline] [CrossRef]

5) Jang HJ, Leigh JH, Seo HG, et al.: Effortful swallow enhances vertical hyolaryngeal movement and prolongs duration after maximal excursion. J Oral Rehabil, 2015, 42: 765-773. [Medline] [CrossRef]

6) Park T, Kim Y: Effects of tongue pressing effortful swallow in older healthy individuals. Arch Gerontol Geriatr, 2016, 66: 127-133. [Medline] [CrossRef]

7) Wheeler-Hegland KM, Rosenbek JC, Sapienza CM: Submental sEMG and hyoid movement during Mendelsohn maneuver, effortful swallow, and expiratory muscle strength training. J Speech Lang Hear Res, 2008, 51: 1072-1087. [Medline] [CrossRef]

8) Logemann JA, Rademaker A, Pauloski BR, et al.: A randomized study comparing the Shaker exercise with traditional therapy: a preliminary study. Dysphagia, 2009, 24: 403-411. [Medline] [CrossRef]

9) Antunes EB, Lunet N: Effects of the head lift exercise on the swallow function: a systematic review. Gerodontology, 2012, 29: 247-257. [Medline] [CrossRef] 